\section{Action-Oriented Design Bridging the Gap between Teaching and Practice through the Application of Action-Oriented Design Methodology}

Karim Najjar

American University of Beirut
The current trend in architectural design pedagogy favors research and innovation that pushes the field into new territories by triggering exciting debates and encouraging new speculative design experimentation. This can be attributed to the enormous increase in the mobility and accessibility of information. Internet and mobility have overwhelmed our design studios with data from different cultures and technologies, thus providing limitless possibilities and opportunities to students and teachers alike. However, architectural practice on the ground is hardly capable of keeping up with the fast-paced nature of academic innovation today because the highly experimental and speculative approaches powering these designs do not often consider the reality of constraints posed by factors such as budget, program, construction feasibility, or building law. It therefore can be argued that there is a growing gap between academia and the profession in architecture today.

This paper therefore aims to introduce and discuss the benefits of action-oriented design methodology as opportunity in bridging the gap between pedagogy and practice. Applied successfully to Design Impact Laboratory (DI-Lab) at the American University of Beirut, such models bring innovative conceptual design work to life through its context in academia. Established in 2016 with the purpose of allowing design innovation to inform community-based projects, DI-Lab has since involved over fifty students in the design and execution of highly innovative, socially conscious projects.

The paper begins by highlighting the significance of sharing values between practice and teaching and argues the importance of implementing design innovation in service of the sustainable development of vulnerable communities. The paper then explores DI-Lab's action-oriented methodology by analyzing how the implementation of various student projects were able to bridge the gap between teaching and practice by integrating professionals and beneficiaries into the process. Projects range from a climatically conscious library for Syrian refugees to the rehabilitation of public space through lightweight, tensile structures, all of which emphasize student-centered learning. Unlike the marginal roles afforded by traditional internships at architectural firms, students at DI-Lab assume ownership and responsibility for real-life projects from conception to completion. This empowerment consequently impacts the role of the teacher in studio, which is further discussed in the second part of the paper. The research reflects on the experiences of students who have participated in DI-Lab and concludes by presenting the lessons learned from the process through a discussion of the limits and opportunities afforded by a comprehensive actionoriented research and design approach.

\section{BRIDGING THE GAP}

The events and developments in politics, society, and culture of the past decades have rapidly shifted the pretext of architectural discourse. The 1960s and 70s introduced community-based design 


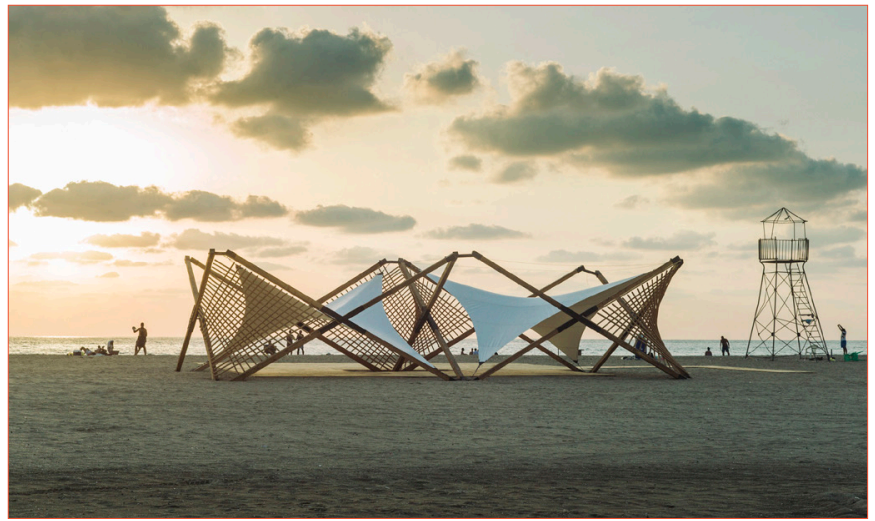

Figure 1. Marah, Tyre Nature Reserve Hub, DI-Lab project. 2017.

as an important dimension of architectural education, a shift due in large part to the social justice movement of that era.

The Wall Street boom of the 1980s spurred the profession to evolve in somewhat different directions. Practice began to prioritize development based corporate design. In academia the architectural discourse moved in a reflective direction that favored the historiography of the field and speculative experimentation, both of which transformed the general understanding of the discipline into one more concerned with a practice of the arts. This development was headed by architectural figures such as Thom Mayn, Peter Cook, and Wolf Prix who were in charge of directing educational programs that were especially influential to students across generations. In parallel, they were also running highly renowned practices, and found recognition as "Starchitects" which cemented the credibility of their concepts in the world of academia. At that point their teaching and practice played reciprocal roles.

Today, twenty years later, the paradigms directing architectural education have shifted once again, with architectural education and academia increasingly leaning towards research in engineering and social science fields. This trend is arguably caused by the quest to actively shape the future of the discipline in relation to the digital revolution, globalization, and pressing social and environmental conflicts. This change is driven in large part today by academic institutions that recognize design education as a form of empirical research in its own right.

A growing interest in teaching and research that engages in speculative design processes capable of exploring the potentials of advancing the architectural disciplines has encouraged the incorporation of specific fields such as algorithmic design and machine learning as well as structural fabrication through robotic arms, 3D printing, and the like. Another field that is gaining momentum in academia is the focus on social and environmental issues such as migration, urbanization, climate change, and resource scarcity. Here architectural discourse is often grounded in social and engineering sciences. These trends consequently require that more specialists engage in architectural education. It can therefore be noted that educational institutions in architecture are currently striving towards design research and less professional education.

In other words, the spectrum that is design research in academia is undoubtably encouraging highly innovative concepts and solutions within the discipline. It is also allowing for opportunities to expand the field of architecture into new territories. This is highly beneficial in that it builds the intellectual capacities of students in preparation for future work. But how far should these speculative processes be entertained? An outsider could rightfully ask how many homes will actually be 3D printed in the near future, and how relevant design guidelines are for upgrading informal settlements if they are not truly tested. Practice is about materializing concepts with a direct impact on the greater community. Real buildings are the ultimate proof of design concepts and values. But these projects are determined by constraints such as time, budget, building law, and the like. This makes it difficult to fully explore the potential of advanced concepts driving architectural design outside the protective walls of educational institutions.

With that in mind, it is not my objective to discuss whether teaching shall inform practice or practice informs teaching. As educator and practitioner, I regard both as necessary entities for the existence of the discipline. The "practice of teaching" is more discourse driven, whereas "teaching of practice" is about imparting the process of decision making. Both are fundamental to design. The question for me is how to possibly bridge the gap and convey the necessity of both teaching and practice. In this sense, many educational institutions have since started complimenting their curriculum with design build workshops that involve both architecture and engineering students.

In 2016, I founded the Design Impact Laboratory (DI-Lab) at the American University of Beirut, with the intention of creating a hybrid setup between academia and practice. The DI-Lab is centered on two principles that are derived from Victor Papanek's understanding of the nature and purpose of design. The lab takes these principles as tools to bridge the gap between teaching and practice. The first principle relies on Papanek's understanding of what design is. In his book, Design for the Real World, he states the following:

"...Design is basic to all human activities. The planning and patterning of any act towards a desire, foreseeable end constitutes the design process. Any attempt to separate design, to make it a thing by-itself, works counter to the fact that is the primary underlying matrix of life" (Papanek 1971).

With this in mind, the lab intends to convey design as a form of human existence beyond academic or professional conventions. It understands design as intrinsic to life and the experience of it, where the process of learning is rooted and reflected in the actions of the designer. The second principle relates to the purpose of design, where 
Papanek writes:

"...design must become an innovative, highly creative, cross disciplinary tool responsive to the true needs of men. It must be more research oriented, and we must stop defiling the earth itself with poorly designed objects and structures" (Papanek 1971).

The lab also understands architectural design as a form of expression that needs to be meaningfully determined by values. It asks students to take action and invest their creative potentials into a design process that has a meaningful impact. DI-Lab consciously disregards the conventions of teaching and practice. It calls on students and instructors to team up as creative humans and turn their efforts towards an action-oriented design in the service of improving conditions for communities and the environment in Lebanon and the region.

\section{DI-LAB OBJECTIVES}

DI-LAB was established at the American University of Beirut's Department of Architecture and Design with the purpose of engaging architecture and engineering students and faculty in the research, design, and implementation of community-based projects in Lebanon and the region. The focus of DI-Lab is on smart structural systems and climate responsive design strategies developed in service of the public good.

DI-Lab builds on the satisfaction of creating things, how they behave in the environment, the experience of the results, and their cognitive interpretation. The scientific knowledge and technical expertise available are substantial. The focus is on innovation, conceptual and lateral thinking, new technologies, construction, interdisciplinary work, and collaboration with craftsmen and industries. Students also learn how real-life constraints determine the process and final result. From initial design conceptualization to prototyping and finalization of the finished product, the students are required to think clearly and respond quickly.

As designs are always presented to stakeholders outside of the academic realm such as end-users, NGOs, or municipalities, students are exposed to the field during which they are required to develop communication skills in order to identify necessary parameters and consequently argue their design proposals.

The other objective of the DI-Lab mission is to serve the local community through the design and implementation of communitybased projects in Lebanon and the region. DI-Lab aims to develop design strategies for emergency projects that exist within postconflict and disaster-prone areas including the damage of vital architectural heritage sites. The lab also works to engage in environmental issues such as marine life protection and renewable energy. It provides design and engineering solutions that intend to improve the living conditions of marginalized communities. It further aims to create a participatory process that engages both beneficiaries and users in order to encourage sustainable development.
The experimental aspect of the laboratory is its strength- this allows for innovation and discoveries. Participants are also challenged to solve design issues by taking into consideration various constraints such as budget, availability of materials, time, and sustainability. This allows students to gain a particular edge, which combines academia and practice that involves know-how of design strategies and construction management methods.

\section{DI- LAB METHODOLOGY}

In 2016, DI-Lab began by teaming up with the AUB Center of Civic Engagement and Community Services on its first project, a library for refugee children in the Bekaa Velley in Lebanon. The project was widely published and gave the lab the edge to design and implement high performance structures professionally within an academic context. This step was an important starting point as it allowed the lab to acquire further projects and funds.

The lab is now integrated into the curriculum of the AUB Department of Architecture and Design and offers two elective courses at the undergraduate level. One elective explores Public Interest Design (PID), an approach through which architectural projects result from a participatory approach that involves the community in the design process. This course intends to support and set the groundwork for the other design build elective, the DI-Lab summer workshop, which takes place over 8 weeks during the summer semester.

The PID elective allows students to explore and compile a framework of research methodologies and case studies through which they have the opportunity to survey the needs of target communities. Based on a collaborative approach, students develop conceptual project proposals which contribute to solving pressing issues challenging society today. Through partnerships with different actors in the community, reciprocal exchanges and ongoing engagements help define the values and needs of the community. Students have the opportunity to interpret those needs through

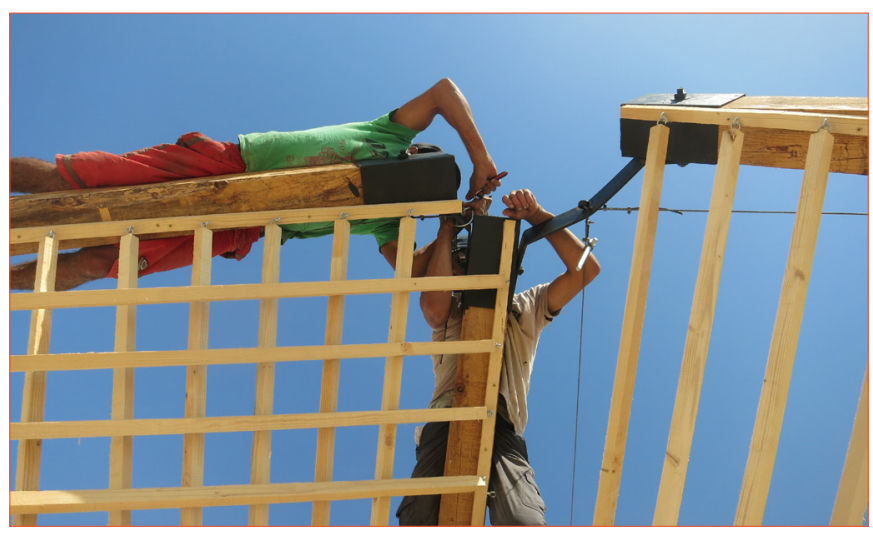

Figure 2. Students' hands on experience. 


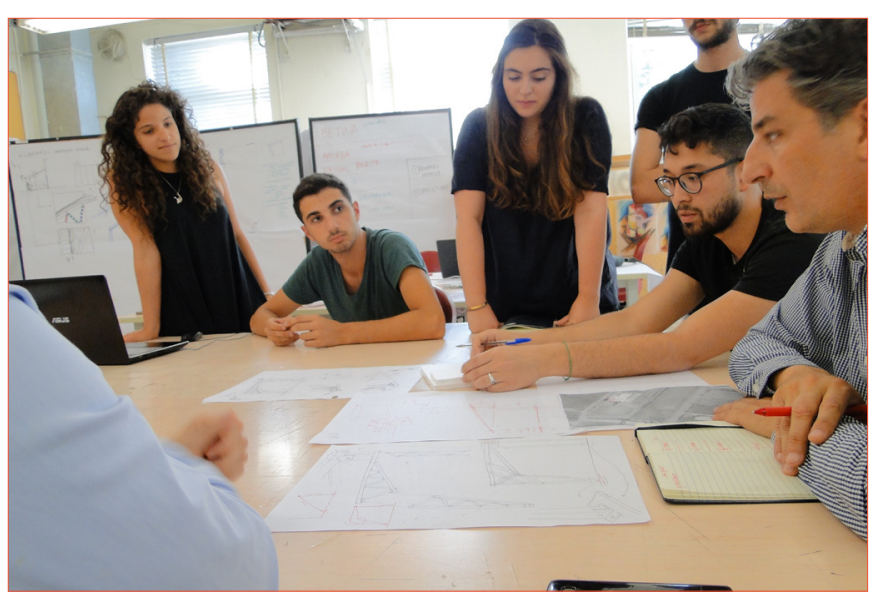

Figure 3. Reviews of project designs in studio.

their knowledge and skills and translate them into responsive project proposals that benefit their surroundings. The outcomes are the result of a participatory process based on communication, interest, trust, value, and involvement, thus making projects economically viable, socially integrated, and culturally accepted.

Through a methodology specific to PID, and based on impact evaluation and a participatory approach, students map stakeholders and identify potential projects responding to the needs of the community. Conceptual project proposals and guidelines are presented to stakeholders as a preparation for other DI-LAB courses where selected potential projects are developed and executed. The objective of the course is to raise awareness about social and environmental issues affecting our communities and prepare students to take responsibility for the sustainable development of our society. Through the multidisciplinary approach based on collaboration, partnerships and inclusive decision-making, students learn how to address humanitarian concerns in the field of architecture and design. Students gain a critical understanding of PID methodologies and apply survey models for community-based design projects. They develop designs, process guidelines, and build contacts with stakeholders and potential donors. Finally, the students are requested to write a comprehensive project proposal that is presented to all parties involved.

The DI-LAB design build workshop offered during the summer semester is structured to engage a group of architecture and engineering students in designing and implementing communitybased projects in Lebanon and the region. Here the Lab adopts an action-oriented design approach within the framework of a professional set up. The experimental aspect of the laboratory is its strength and allows for both innovation and discovery. Activities performed within the scope of the lab require participants to innovate and respond rapidly to specific tasks. These tasks incorporate design, execution drawings, cost calculation, and site supervision. A rapid assessment of the actors, context, architectural typologies, problematics and potential entry points is presented to the participants. Students develop hands on skills and experience how their proposals can make a significant impact on the ground. This allows students to gain a particular edge that introduces the practice to an academic set up.

In groups of four to eight, students are tasked with designing and executing a specific project. Each group is responsible for maintaining an adequate momentum and assigning responsibilities amongst themselves. Daily meetings are held to discuss different tasks and progress. The course starts with site visits and meetings with stakeholders. Here they learn to verify opportunities and constraints for a project. Then students return to the drawing board and explore design strategies that lead to specific proposals. Exploring the feasibility of project implementation is a key issue that is new to students. Given the short period of the workshop, they design in parallel to material studies and estimation of quantities and costs. Students learn the importance of integrating structural efficiency and construction techniques into the design process. Early on in design, professional consultants such as structural and climate engineers are invited to discuss the proposals at a conceptual level. Students experience the value of an interdisciplinary design process as a necessary means of innovation.

After a period of two to three weeks, the groups present their design proposals to stakeholders such as NGOs or municipalities. For the first time students experience discussion and feedback from people with other backgrounds and interests- a crucial experience of the practice. Once design is completed and the funding is secured, the groups of students further develop the proposals in collaboration with engineers, craftsmen and suppliers. They build mockups to be tested for execution and submit a full set of construction documents and bill of quantities. For the first time in their careers, students discuss their designs with professional builders and suppliers and understand the particularities of design and execution, as well as the importance of negotiating ideas versus built constraints. This phase exists across two to three weeks. In the remaining weeks, the students work hand in hand with craftsmen and builders to

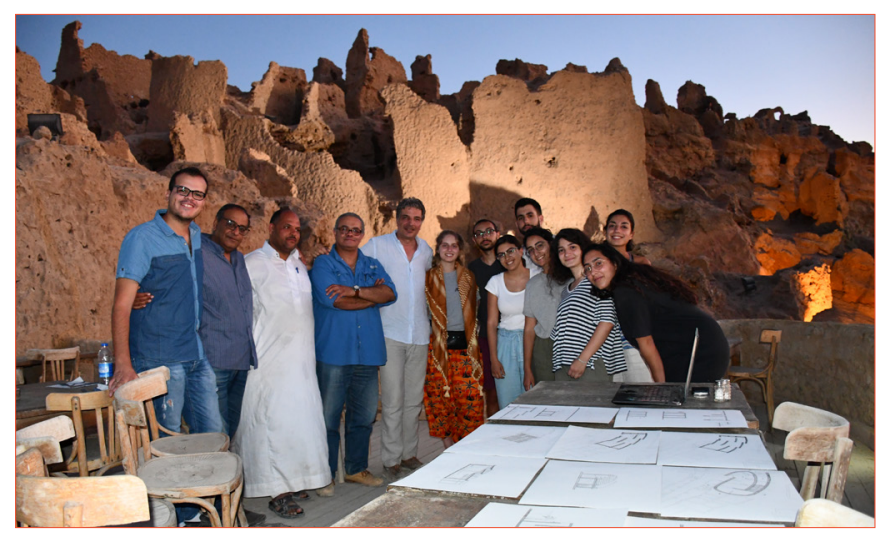

Figure 4. Student presentation of project proposals in Siwa, Egypt, to partners. 
execute the project. This is the most exciting part as they witness the rapid materialization of their work. In this phase they learn that the construction practice is also a creative process that requires them to be both responsive and attentive.

Given this hybrid nature of teaching and practice that is offered at DI-Lab, the role of teaching is thus shifted, and requires that students direct themselves and assume responsibility. The instructor is simply part of the team, an active participant in the process as both a designer and colleague. Because of formal contracts and deliverables at stakes, the instructor has to bring in his/her expertise and experience of the practice to support and guide the students on a daily basis.

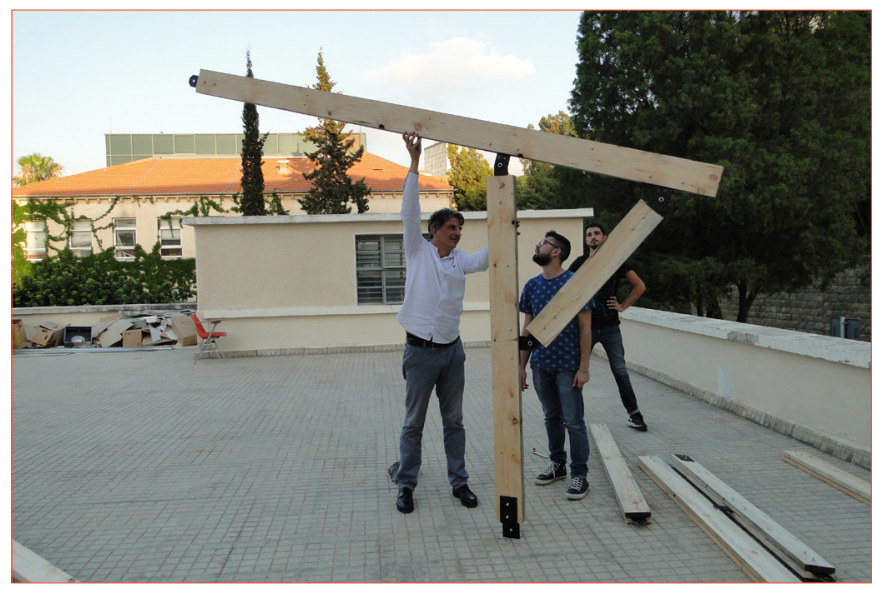

Figure 5. Testing structures and mechanisms.

\section{STUDENT EXPERIENCES}

In conclusion I believe that student commentary can provide an adequate picture of the learning experience created at DI-Lab:

"The Di-Lab course was truly one of the few studios where one can get creative and experiment while at the same time enjoy the process of implanting a real scale project. It offered us an amazing opportunity to examine, in an action-oriented research approach, how the application of a lightweight and temporary system can have a social and programmatic impact on the public beach of Tyre."

Lea Ramadan

"Through DI-Lab, I was able to learn and explore the different factors informing an architect's job. From meeting the clients, concept design presentations, and on-site execution, I was finally involved with the realities of the practice. In addition, and through di lab, we were able to use our design thinking skills in order to serve our community and raise awareness on actual socio-economic and environmental issues in our cities."
Nella Abi Khalil

"In DI-Lab, I mainly designed construction details. I was actually able to be part of their manufacturing and implementation on site. It was very fulfilling to see my details get executed. They were also published on Archdaily, of which I am very proud."

Sari Kantari

"The DI-Lab experience is different from any other internship. It permitted us students to share ideas from design strategies to representation and learn how to work together as a team. It also made me realize how important a project can be to a community of people and how as an architect it is my responsibility to always respect their opinion and needs."

Nirvana Kobeissi

\section{PROJECT EXAMPLE}

\section{"Shams"}

Library for refugee children / Majdel Anjar / Lebanon, 2016

With over 700,000 children currently out of school, youth have become the most vulnerable in the wake of the Syrian refugee crisis. With the ability to secure the futures and livelihoods of refugee children, education is key to overcoming the crisis. With this in mind, the team, along with design students from The American University of Beirut, explored the conditions of refugee schools in the Bekaa region of Lebanon. Site visits revealed that education is severely challenged by a lack of adequate learning environments. High CO2 emissions and extreme fluctuations in temperature make classrooms too hot in summer and cold in winter, therefore causing severe thermal discomfort for students. The conditions, along with insufficient lighting, have created significantly inadequate learning environments.

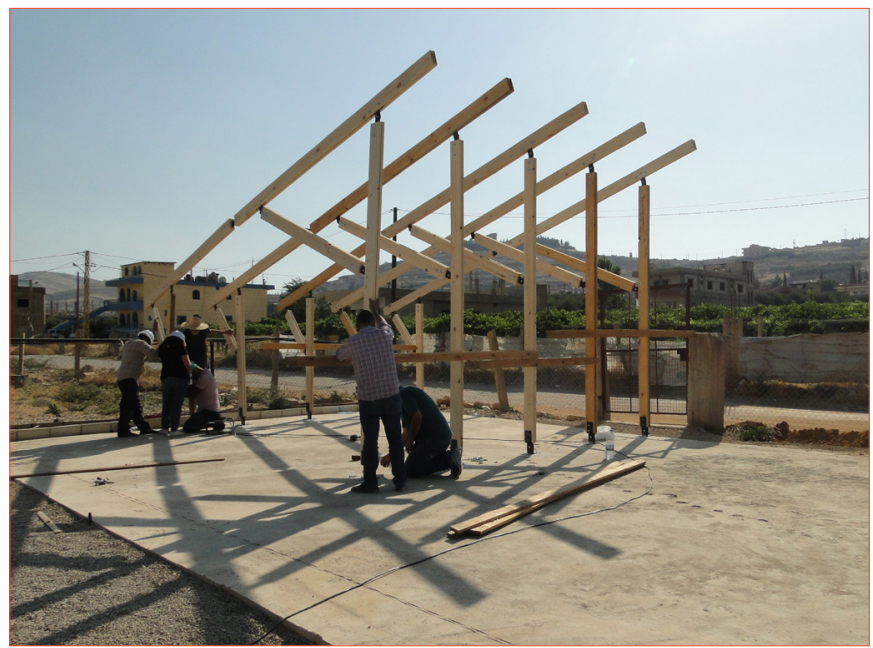

Figure 6. Building the Shams Library in the Bekaa, Lebanon. 


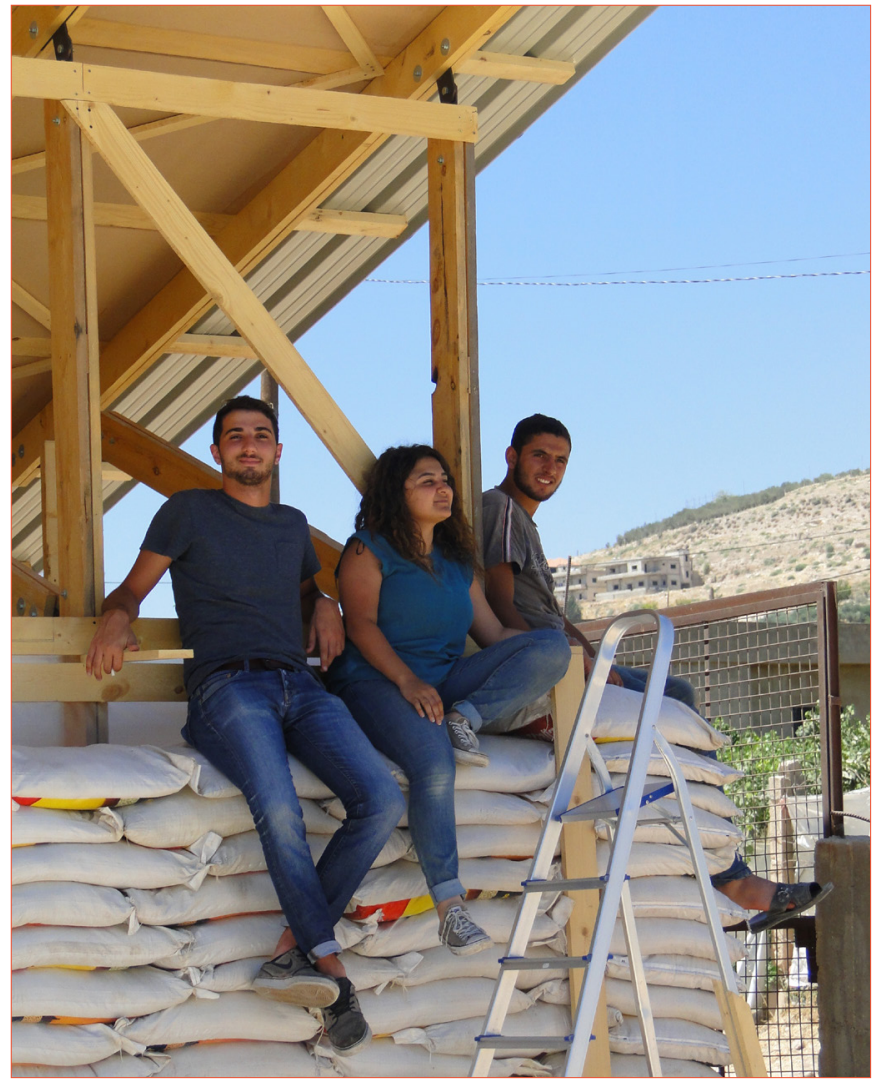

Figure 7. Use of innovative methods and local materials to optimize the design.

Following these observations, DI-Lab teamed up with the Kayany Foundation and AUB's CCECS who are currently operating the Majdel Anjar School for refugees to integrate a library as an informal learning area that would benefit from passive climatic design strategies capable of optimizing learning conditions. Developed as a deployable system, the structure was designed with relocation and cost-efficiency in mind. The interdisciplinary team of students and professionals applied their action-oriented approach by placing design experimentation and innovation at the core of the creative process.

Structural experimentation allowed the team to overcome a number of challenges proposed by the project itself, including costefficiency and material limitations. One such challenge to overcome was the large 7 by 9 -meter span of the project. Trial models and innovative prototypes led the team to design a three-hinged arch that allowed for the use of locally sourced wooden studs capable of overcoming the wider spans. Connected with steel members, the frames were able to be prefabricated by students in the studio, therefore reducing construction time and ultimately allowing for faster installation on site. The framing system was then filled in with sandbag walls that provide both excellent insulation and sufficient thermal mass as a means of combatting overheating. A geothermal cooling and heating system was also applied to further develop the project's thermal comfort. The 40-meter long earth duct provides the library with cool air in the summer and warm air during the winter. This is achieved by the air velocity propelled through the stack ventilation in the double roof system.

Following the completion of the project, interior temperatures were monitored with sensors over a year, with extensive data analysis revealing the success of the passive cooling and heating system. Moderate interior temperatures were achieved across each season thus ensuring that a comfortable climate was maintained year-round. The Shams library prototype was in turn very positively received by the schoolchildren and has since become their favorite place to visit and learn. Shams demonstrates the importance of design innovation in addressing humanitarian issues and has since found international recognition in the media through numerous articles and publications.

Design:

DI-Lab, Department of Architecture and Design, American University of Beirut

Instructors:

Karim Najjar, Balsam Madi, Ahmad Nouraldeen

Students:

Betina Abi Habib, Natasha Bou Akl, Andrea Comair, Mohamad Deeb, Joseph El Jadam, Tina Najia, Mohamad Nazar, Fayssal Yatim

Partners and Consultants:

Transsolar Climate Engineering (Christian Frenzel) / AUB Center of Civic Engagement and Community Services (Rabih Shibli)

Client:

Kayany Foundation NGO (Nora Jumblatt)

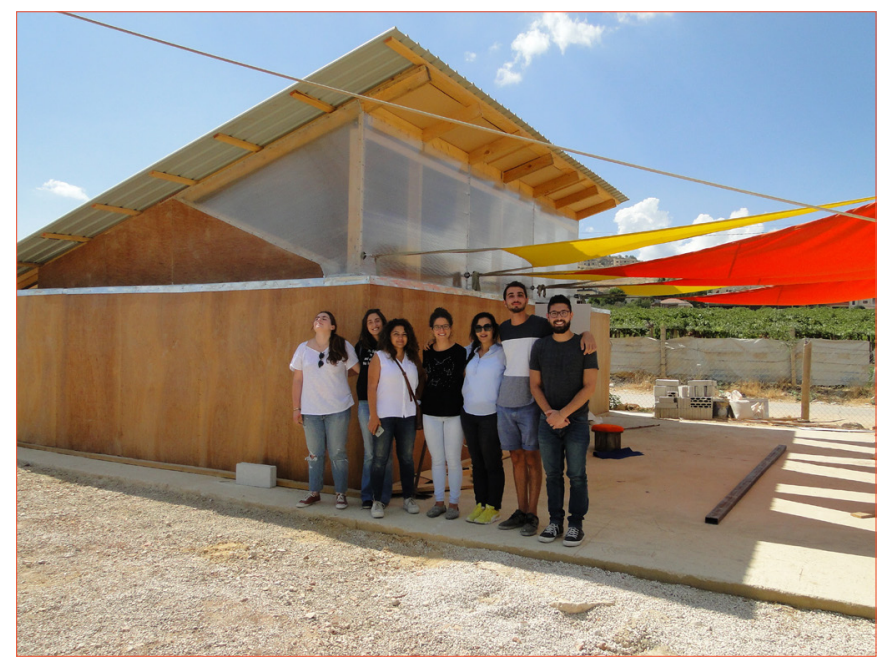

Figure 8. The Shams Library. 


\section{Notes}

1. Papanek, Victor. Design for the Real World: Academy Chicago Publishers, 1971

2. Fathy, Hassan. Architecture for the poor. Chicago: University of Chicago Press, 1973

3. Weber, Willi. Yannas, Simos. Lesson from Vernacular Architecture: Routledge 2014

4. Rudofsky, Bernard. Architecture without Architects: University of New Mexico Press 1987

5. Hurx, Merlijn. Architecture as Profession: Brepols Publishers 2018

6. Owen, Graham. Architecture, Ethics and Globalization: Routledge 2009

7. Harriss, Harriet. Widder, Lynnette. Architecture Live Projects: Routledge 2014

8. Stonorov, Yolya. The Design Build Studio: Routledge 2018

9. Abendroth, Lisa M. Bell, Bryan. Public Interrest Design Education Guidebook: Routhledge 2018

10. Bell, Bryan. Wakeford Katie. Expanding Architecture: Metropolis 2008 